\title{
Seasonal patterns in metazoan parasite community of the "Fat Sleeper" Dormitator latifrons (Pisces: Eleotridae) from Tres Palos Lagoon, Guerrero, Mexico
}

\author{
Juan Violante-González ${ }^{1}$, Agustín Rojas-Herrera ${ }^{1} \&$ Ma. Leopoldina Aguirre-Macedo ${ }^{2}$ \\ 1. Unidad Académica de Ecología Marina, Universidad Autónoma de Guerrero, Gran Vía Tropical No. 20, Fracc. Las \\ Playas. A.P. 39390, Acapulco Guerrero, México; viojuang@yahoo.com.mx \\ 2. Laboratorio de Parasitología, Centro de Investigación y Estudios Avanzados del Instituto Politécnico Nacional \\ (CINVESTAV-IPN) Unidad Mérida, Carretera Antigua a Progreso Km 6, A.P. 73 Cordemex, 97310 Mérida, Yucatán, \\ México; leo@mda.cinvestav.mx
}

Received 23-IV-2007. Corrected 30-VI-2008. Accepted 31-VII-2008.

\begin{abstract}
Dormitator is among the most important fish genera in the Mexican Pacific coastal lagoon systems. In Tres Palos Lagoon, the Fat Sleeper Dormitator latifrons is one of the most significant species based on catch volume, although it is only consumed locally. Very little information exists on this species' parasitofauna. Composition and temporal variation in the metazoan parasite community structure of Dormitator latifrons from Tres Palos Lagoon (99 $47^{\prime}$ W, $16^{\circ} 48^{\prime}$ N), Guerrero, Mexico, were determined using seasonal samples taken between April 2000 and June 2002. Ten parasite species (55 817 individuals) were recovered from 219 examined hosts. These species included eight helminths (Ascocotyle (Phagicola) longa, Echinochasmus leopoldinae, Clinostomum complanatum, Pseudoacanthostomum panamense, Saccocoelioides lamothei, Parvitaenia cochlearii, Contracaecum sp. and Neoechinorhynchus golvani) and two crustaceans (Argulus sp. and Ergasilus sp.). Five of the helminth species exhibited seasonal variation in their infection dynamics associated with environmental changes during the dry and rainy seasons. The variations in the infection dynamics generated changes in the community structure over time. Rev. Biol. Trop. 56 (3): 1419-1427. Epub 2008 September 30.
\end{abstract}

Key words: Mexico, Dormitator latifrons, parasite communities.

The Eleotridae family consists of 150 fish species distributed in 35 genera found principally in the tropics and subtropics. Species in this family are largely permanent inhabitants of coastal lagoons and estuarine systems, although certain groups are exclusive to freshwater environments (Castro-Aguirre et al. 1999). Dormitator is one of the most important fish genera in the Mexican Pacific coastal lagoon systems. In Tres Palos Lagoon (99 $47^{\circ}$ W, $\left.16^{\circ} 48^{\prime} \mathrm{N}\right)$, Dormitator latifrons is one of the most significant species based on catch volume (Pilo-Guzmán 2003), although it is only consumed locally. Very little information exists on this species' parasitofauna (Pérez-Ponce de León et al. 1999, Garrido-Olvera et al. 2004), despite its importance as a fishing resource, its heavy use as food and its recent use in aquaculture applications (Castro-Rivera et al. 2005).

One of the less studied aspects of tropical parasite community ecology is whether or not these communities experience temporal changes in structure and species composition in response to seasonal variations in biotic and abiotic environmental factors (SalgadoMaldonado 1993, Jiménez 2003, Pineda-López 1994, Violante-Gonzalez et al. 2008) determining the roles of different parasite species within a community, and if their infection levels are constant and predictable over time is vital to implement biological control methods in culture systems. Recently, Violante-Gonzalez et al. (2008) found temporal variation in parasite communities of this fish host at the same 
locality though one year, but in other to know wether this variations remains over time, data were collected over five seasons (dry and rainy along 3 years) to: 1.- characterize its parasite community; and 2.- determine if its parasite community experiences seasonal paterns in structure and species composition, through several years.

\section{MATERIALS AND METHODS}

A total of 219 D. latifrons specimens with total lengths ranging from 13.6 to 26.3 $\mathrm{cm}(21.2 \pm)$ were collected over five climatic seasons (April 2000 to June 2002) from Tres Palos Lagoon, in the state of Guerrero, Mexico (Table 1). A complete necropsy was done on all host specimens, including all organs except the blood. Internal and external metazoan parasites collected from the hosts were processed according to the methods described by Lamothe-Argumedo (1997) and VidalMartínez et al. (2001). All helminths recovered from each fish were counted. Digeneans (adults and metacercariae), cestodes, and nematodes were fixed in AFA (formalin-ethanol-acetic acid). Acanthocephalans were placed in distilled water and refrigerated overnight (6-12 h) to evert the proboscis, then fixed in $70 \%$ ethanol. Digenean, cestodes, and acanthocephalans were stained with carmine. Nematodes were cleared with glycerine for light microscopy and stored in $70 \%$ ethanol. A species-richness sampling effort curve (Aho et al. 1991) was used to determine if sample size was sufficient to recover the highest proportion of parasite species and therefore accurately characterize the component communities. Voucher specimens of almost all taxa were deposited in the Colección Nacional de Helmintos, Instituto de Biología, Universidad Nacional Autónoma de México, Mexico City.

Autogenic parasite species were defined as those that reach maturity in aquatic hosts and thus have a limited ability to colonize new locations. Allogenic species were those with birds or mammals as definitive hosts and whose natural migrations favor dispersion, giv- ing them a wide geographic distribution (Esch et al. 1988). The host range concept (Rohde 2005) was used to classify the parasite species as specialists or generalists. According to this concept, a specialist parasite species is one that has a marked affinity for a specific host family, genus or species, while a generalist is one that parasitizes a number of families.

Variation in species composition over time was described using prevalence (percent of hosts infected), mean abundance (mean number of parasites per examined fish), expressed as mean \pm standard deviation, and the range of intensity (Bush et al. 1997) for each helminth species per sampling period. To determine possible differences in infection parameters between sampling periods, $G$ tests were used for prevalence and a one-way ANCOVA for abundance, with total length as a covariate to control the influence of host size. The significance of all statistical analyses was established at $\alpha=0.05$.

Community analysis: analyses were taken to the component community and infracommunity levels (Holmes and Price 1986), that is, all the helminthes in all the hosts collected per sampling period and all the helminthes in an individual fish respectively. The component community parameters included total number of parasite species, total number of individual parasites, the Shannon-Wiener Index $(\mathrm{H})$ as a measure of diversity and the Berger-Parker Index (BPI) as a measure of numerical dominance. Kruskal-Wallis tests were used to determine significant differences in the component community parameters between sampling periods at this level. The infracommunities were described by the mean number of helminth parasite species per fish, mean number of parasite individuals per fish and the mean value of the Brillouin Diversity Index (H') per fish. A oneway ANCOVA was used to determine significant differences in infracommunity parameters between sampling periods. Correlations were made using the Spearman range coefficient $\left(\mathrm{r}_{\mathrm{s}}\right)$ (Krebs 1999). 
TABLE 1

Parasite species of Dormitator latifrons from Tres Palos lagoon, Guerrero, México

Site

CNHE $\mathrm{Au} / \mathrm{Al}$ N/Season $\mathrm{P}(\%) \quad$ Total

Abundance

Range of

Intensity

\section{DIGENEA}

Saccocoelioides

Intestine 5920

lamothei, Aguirre-

Macedo \& Violante-

González 2008

Ascocotye (Phagicola)

longa

Heart,

mesentery,

Ransom 1920

liver

Clinostomum

complanatum

Rudolphi 1814

Liver,

mesentery,

muscle, body

cavity

Echinochasmus

leopoldinae

Scholz, Ditrich \&

Vargas 1996

Pseudoacanthostomum panamense Caballero, Bravo-Hollis 1953

Gills,

muscle,

inside

intestine wall

Gills, inside
stomach wall

49

911 A

$\mathrm{Au}$

24/D00

12.5

73/R00 37.0

48/D01 56.3

50/D02 54.0

24/R02

50.0

6

$1-3$

489

$6.7-18.1$

$1-98$

256

$5.3-10.1$

2-34

2134

$42.7-102.6$

$1-426$

$19.5-19.7 \quad 18-72$

$\begin{array}{lllll}4901 \quad \mathrm{Al} & 24 / \mathrm{D} 00 & 8.3 & 6\end{array}$

73/R00

$0.3-1.4$

0.01

2-4

$50 / \mathrm{D} 02 \quad 4.0 \quad 6$

$0.1-1.4$

1-1

24/R02 $8.3 \quad 1$

0.1

2-4

$\begin{array}{lllll}5007 & \mathrm{Al} & 24 / \mathrm{D} 00 & 29.2 & 226\end{array}$

$9.4-56.6$

$1-1$

73/R00 $\quad 16.4 \quad 24$

48/D01 $12.5 \quad 75$

50/D02 $32.0 \quad 202$

24/R02 $8.3 \quad 20$

$0.3-1.8$

4-160

$1.7-18.8$

$1-7$

$4.1-15.7$

$1-50$

1.7

1-29

$1-20$

$476.6-180.6 \quad 366-1050$

$\begin{array}{llllr}\text { 73/R00 } & 30.1 & 3690 & 50.6-291.2 & 2-710\end{array}$

48/D01 $39.6 \quad 6233 \quad 130.0-399.0 \quad 3-1355$

50/D02 76.0 $13105 \quad 262.1-326.2 \quad 3-1050$

24/R02 $50.0 \quad 4558$

$379.8-383.6$

$300-1400$

$4904 \quad \mathrm{Au} \quad 24 / \mathrm{D} 00 \quad 54.2$

95

$4.0-6.8$

$1-25$

73/R00 $14.0 \quad 65$

$0.9-4.0$

1-25

48/D01 $16.7 \quad 40$

$0.8-5.0$

1-13

50/D02 $50.0 \quad 197$

$4.0-6.1$

$1-16$

24/R02 $25.0 \quad 11$

$1.0-5.0$

1-9

\section{NEMATODA}

Contracaecum sp. von Intestine,

Drasche 1882

mesentery,

liver, muscle

$\begin{array}{cccccc}\text { Al } & \text { 24/D00 } & 8.3 & 17 & 1.0-11.0 & 1-16 \\ & \text { 73/R00 } & 8.2 & 16 & 0.2-1.4 & 1-5 \\ & \text { 48/D01 } & 8.3 & 6 & 0.1-0.6 & 1-2 \\ & \text { 50/D02 } & 18.0 & 30 & 1.0-4.6 & 1-15\end{array}$

CESTODA

Parvitaenia cochlearii Liver

Coil 1955

491

24/D00

8.3

7

$0.3-0.7$

3-4

52.0

1238

$17.0-41.1$

5-200

48/D01 33.3

229

50/D02

58.0

$4.8-22.7$

$1-80$

24/R02

58.3

53

$1-92$

$4.4-4.0$

4-11

ACANTHOCEPHALA

Neoechinorhynchus

Intestine

492

$\begin{array}{ccc}\text { 24/D00 } & 100 & 1376 \\ \text { 73/R00 } & 92.0 & 1539 \\ \text { 48/D01 } & 94.0 & 1090 \\ \text { 50/D02 } & 100 & 2959 \\ \text { 24/R02 } & 100 & 207\end{array}$

$57.3-64.0$

4-30

$21.1-22.0$

1-98

Salgado-Maldonado

1978

$23.0-35.0$

$59.2-47.2$

$1-200$

9-269

$17.3-11.1 \quad 2-32$ 
TABLE 1 (Continued)

Parasite species of Dormitator latifrons from Tres Palos lagoon, Guerrero, México

\begin{tabular}{|c|c|c|c|c|c|c|c|c|}
\hline Parasite & Site & CNHE & $\mathrm{Au} / \mathrm{Al}$ & N/Season & $\mathrm{P}(\%)$ & Total & Abundance & $\begin{array}{l}\text { Range of } \\
\text { Intensity }\end{array}$ \\
\hline \multicolumn{9}{|l|}{ CRUSTACEA } \\
\hline \multirow[t]{2}{*}{ Argulus sp. } & Skin, fins & & $\mathrm{Au}$ & 73/R00 & 4.1 & 3 & 0.04 & $1-1$ \\
\hline & & & & 50/D02 & 2.0 & 1 & 0.02 & $1-1$ \\
\hline \multirow[t]{5}{*}{ Ergasilus sp. } & Gills & & $\mathrm{Au}$ & 24/D00 & 75.0 & 329 & $14.0-17.0$ & $1-62$ \\
\hline & & & & 73/R00 & 70.0 & 646 & $9.0-11.1$ & $1-51$ \\
\hline & & & & 48/D01 & 48.0 & 314 & $7.0-16.0$ & $1-56$ \\
\hline & & & & 50/D02 & 74.0 & 522 & $10.4-12.4$ & $1-47$ \\
\hline & & & & 24/R02 & 83.3 & 356 & $30.0-19.0$ & $11-67$ \\
\hline
\end{tabular}

CNHE: National Helminth Collection. Colonization strategy: $\mathrm{Au}=$ autogenic species, $\mathrm{Al}=$ allogenic species. $\mathrm{N}=$ number of examined host. Seasons: Dry (D, December-May), Rainy (R, June-November). P(\%) = infection prevalence (\% infected). Total $=$ total number of individual parasites. Abundance (number of parasites per examined fish \pm standard deviation). Intensity (range, min-max).

\section{RESULTS}

Community characterization: a total of ten metazoan parasite species were identified in the 219 D. latifrons specimens examined: five digeneans; one cestode; one acanthocephalan; one nematode and two crustaceans. Six parasite species were found in larval form parasitizing different organs, such as the heart, liver, mesentery, muscles and gills (Table 1). In contrast, only one digenean (S. lamothei) and the acanthocephalan (Neoechinorhynchus golvani), both intestinal parasites, were recovered in adult stage. Five of the species recovered in larval stage were classified as allogenic; the autogenic species included the two species recovered in adult form, as well as the metacercariae of Pseudoacanthostomum panamense (Table 1). All the parasite species recovered were classified as generalists.

The frequency distributions of the parasite species in all the samples showed the community was made up of two groups: common parasites, with prevalence greater than 25\% (N. golvani, Ergasilus sp., Echinochasmus leopoldinae, Saccocoelioides sp., Parvitaenia cochlearii and Pseudoacanthostomum panamense); and rare parasites, with prevalence less than $25 \%$. The most frequent species were also the most abundant (mean abundance $>10$ parasites).

Parasite infection dynamics: the prevalence of four parasite species differed significantly between seasons (Table 1$)$. The digeneans $C$. complanatum $(\mathrm{G}=8.79, \mathrm{p}<0.05)$ and E. leopoldinae $(\mathrm{G}=39.61, \mathrm{p}<0.05)$ exhibited higher prevalence in 2000 and 2002 dry seasons. S. lamothei had higher prevalence in 2001 and 2002 dry seasons $(\mathrm{G}=30.68$, $\mathrm{p}<0.05$ ), and $P$. cochlearii had higher prevalence in 2000 rainy season and 2002 dry season. These four species, in addition to $N$. golvani, exhibited variable mean abundance over time (Table 1). The species E. leopoldinae (one-way ANCOVA F $=42.95, \mathrm{p}<0.05$ ) and $N$. golvani (one-way ANCOVA F=7.85, $\mathrm{p}<0.05$ ) had their highest abundances in two dry seasons (2000 and 2002), while C. complanatum (one-way ANCOVA F=10.06, $\mathrm{p}<0.05$ ) and $S$. lamothei (one-way ANCOVA F=6.65, $\mathrm{p}<0.05$ ) had theirs during just one dry season. Only the cestode $P$. cochlearii had its highest abundance during a rainy season (2000).

Component community: based on cumulative species curves, it was determined that $90 \%$ of the recorded parasite species could 
have been recovered by examining not more than 20 fish hosts. No correlation was observed between sample size and any of the parameters at the two levels (Spearman $p>0.05$ ). The number of parasite species recovered from the samples varied from eigth to ten (Table 2) and was significantly higher during the 2000 rainy season and 2002 dry season (Kruskal-Wallis $\mathrm{H}=8.52, \mathrm{p}<0.05)$. Total number of parasites collected per season ranged from 4540 (2002 rainy season) to 19578 (2002 dry season), and was consistently higher during the three dry seasons (Kruskal-Wallis $\mathrm{H}=9.22, \mathrm{p}<0.05$ ). Echinochasmus leopoldinae numerically dominated the parasite species community during both seasons (Table 2). The Shannon-Wiener diversity index values ranged from 0.85 to 2.06 bits/ind. Comparison between seasons indicated that diversity did not vary between seasons $(p>0.05)$.

Infracommunity: all $D$. latifrons specimens examined were infected and the number of parasite species per infected host range from 1 to 8 . Only $5 \%$ of the hosts were parasitized by a single species, while $95 \%$ had mixed infections: $28 \%$ had 3 species; $39 \%$ had from 4 to 5 ; and $3 \%$ had from 7 to 8 . Based on all samples, total host length was positively correlated with number of parasite species $\left(\mathrm{r}_{\mathrm{s}}=0.258, \mathrm{p}<0.05\right.$, $\mathrm{n}=219)$ and number of individual parasites $\left(r_{\mathrm{s}}=0.320, \mathrm{p}<0.05, \mathrm{n}=219\right)$.

Mean number of parasite species ranged from $3.1 \pm 1.1$ to $4.4 \pm 1.6$, and was significantly higher in the 2002 dry season (ANCOVA $\mathrm{F}=13.1, \mathrm{p}<0.05)$. Mean number of individual parasites varied between $105.6 \pm 180.2$ and 562 \pm 263.1 , and was highest during the 2000 and 2002 dry seasons (ANCOVA $\mathrm{F}=24.4, \mathrm{p}<0.05$ ). Mean diversity (Brillouin index) ranged from $0.78 \pm 0.3$ to $1.2 \pm 0.5$, but did not vary between season $(\mathrm{p}>0.05)$

\section{DISCUSSION}

All species found have been previously reported in this location (Garrido-Olvera et al. 2004; Violante-Gonzalez et al. 2008). Of the
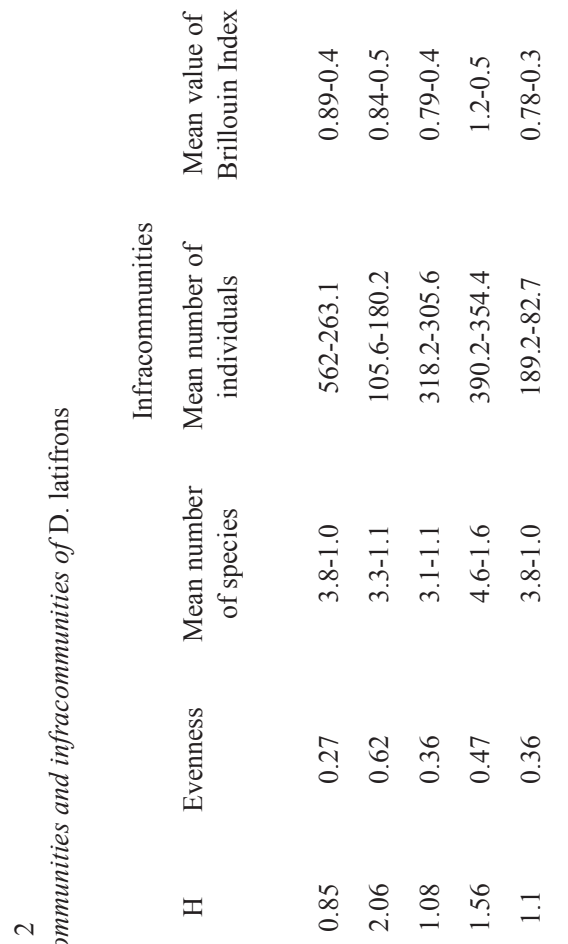

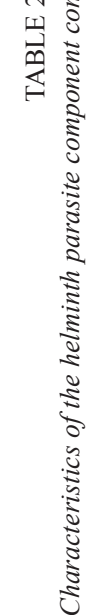

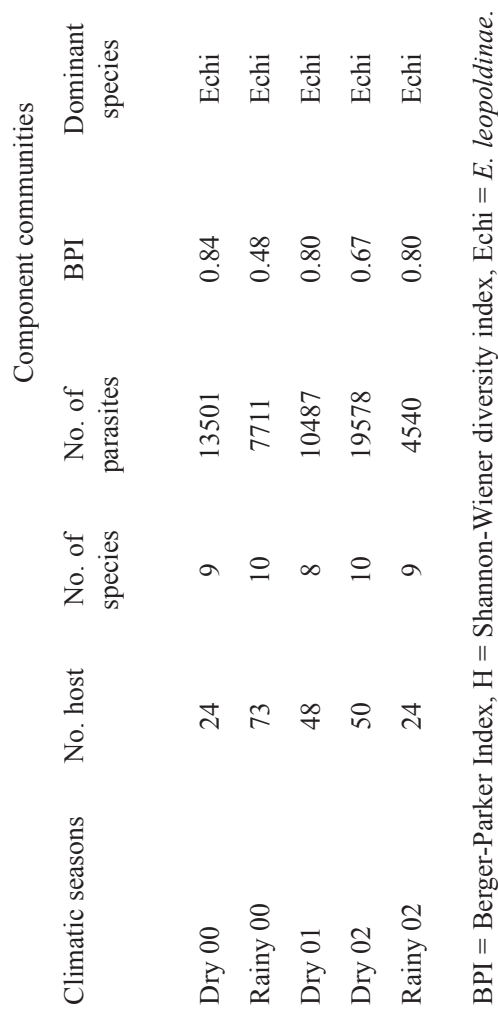


identified helminth species, only three were classified as autogenic because they mature in aquatic hosts: the digenean $S$. lamothei and the acanthocephalan $N$. golvani (both mature in $D$. latifrons); and the digenean $P$. panamense, which matures in Sciades guatemalensis. The other five species (in larval form) all mature in the piscivorous birds Casmerodius albus and Phalacrocorax olivaceus, found at Tres Palos Lagoon (data not included), and were thus classified as allogenic: C. complanatum; E. leopoldinae; Ascocotyle (Phagicola) longa; P. cochlearii; and Contracaecum sp.

The high abundance of allogenic species in the D. latifrons parasite community indicates that the numerous and permanent piscivorous bird population inhabiting the lagoon margins heavily influences this host's parasite community composition. These bird species act as final hosts to the allogenic parasites and then disperse most of these parasite species. This is supported by the high number of larval helminthes in the community $(5 / 8)$, which suggests that $D$. latifrons functions as an intermediary host (Zander et al. 1999) for helminth parasite species in Tres Palos Lagoon.

Many of the most abundant and frequent helminth parasite species, such as C. complanatum, E. leopoldinae, S. lamothei and N. golvani, exhibited clear seasonal variations in their infection dynamics. Environmental stability and host feeding patterns most likely play an important role in determining seasonal variations in abundance for some of the studied helminths, especially those with short life-cycle such as $N$. golvani and S. lamothei. The higher abundance of some parasite species, such as C. complanatum and E. leopoldinae, during the dry seasons probably resulted from the higher environmental stability in Tres Palos Lagoon during this season favoring their transmission process. In contrast, the higher abundance of $N$. golvani and S. lamothei in the dry seasons may be linked to higher host feeding activity levels during the season. During its July to October (rainy season) reproductive period (data not shown), D. latifrons reduces its feeding activity, meaning that intestinal helminths such as $N$. golvani and S. lamothei had lower abundance during this season (Table 1). This is supported by reports showing that seasonal variation in the diet and amount of food ingested by hosts is clearly linked to parasite community population dynamics and structure (Fiorillo and Font 1999, Fellis and Esch 2004, Zander 2004, 2005).

During the rainy season (July to December), environmental conditions in the lagoon become unstable in response to high volumes of organic matter contributed by the contiguous Sabana River. This enhances productivity (Stuardo and Villarroel 1974), and favors transmission of helminths that use copepods as primary hosts, such as the allogenic cestode $P$. cochlearii (Table 1).

In D. latifrons, component community was generally poor in number of parasite species and lower in diversity compared to other tropical freshwater fish species such as Cichlasoma (Nandopsis) urophthalmus (38 species), Parachromis managuensis (34) and Thorichthys hellerin (32) (Salgado-Maldonado et al. 2005). The low species richness in D. latifrons may be attributed to physiological, reproductive and feeding behavior factors (Kennedy et al. 1986, Bush et al. 2003). Yañez-Arancibia and Díaz-González (1977) reported that $D$. latifrons in Tres Palos Lagoon primarily feeds on detritus and plant remains, which may also explain this host's low intestinal helminth richness (two species). The richest intestinal helminth assemblages in tropical freshwater fish are generally observed in hosts with diets based on macroinvertebrates and fish, while herbivores and detritivores will generally have poorer intestinal helminth communities (Choudhury and Dick 2000).

Another possible explanation for the low parasite species richness in D. latifrons may be related to the low complexity food web structure in Tres Palos Lagoon. Food web structure is known to determine parasite species richness and diversity in freshwater systems (Marcogliese 2001). Zooplankton is not very diverse in this lagoon system and macrobenthos and mollusks are scarce: they are represented by just six species (Stuardo and 
Villarroel 1974). This system's poor food web structure clearly restricts intermediary host availability (Marcogliese 2001).

The infracommunities presented the same pattern that the component communities, that is, they were also species-poor, highly numerically dominated and not highly diverse. This coincides with the general pattern observed in the communities of freshwater fish (Kennedy et al. 1986, Kennedy 1990). The positive significant correlation of mean number of parasite species and mean parasite intensity with total host length indicates that larger hosts harbored more parasite species and more parasite burden than smaller ones. This is attributed to the fact that larger (i.e. older) fish, have had more time to accumulate parasites than younger (smaller) ones (Poulin 2000, Bush et al. 2003, Zander 2004).

The main factors structuring these infracommunities were the same ones responsible for structuring the component communities (Holmes 1990, Zander 2004). These factors were host feeding behavior and the availability of free-swimming larvae, both of which are influenced by the dry/rainy season cycle. These two factors structured the infracommunities through accumulation of parasite species from free-swimming cercariae (C. complanatum, E. leopoldinae), encysted metacercariae (Saccocoeloides sp.) or infected (crustacean) prey ( $N$. golvani and $P$. cochlarii). The structuring is completed by acquisition of other rare species.

In line with the component community level, the infracommunities exhibited seasonal changes in their structure that can be attributed to changes in the infection dynamics of the most abundant and frequent (common) parasite species.

Overall, D. latifrons does not have a very diverse parasite community, but its parasite load (i.e. the total number of individual parasites) can be very high, mainly during dry seasons. This is vital to consider in terms of its consumption by the local human population, and its effect in aquaculture applications. The results also indicate that environmental changes caused by the dry/rainy season cycle are the principal factor generating the observed temporal variation in the infection dynamics of the most common parasite species in Tres Palos Lagoon. This cycle also affects the feeding and reproductive behavior of $D$. latifrons, thus modifying its exposure to certain parasite species. The consequent seasonal variation in parasite species infection dynamics leads to changes in the parasite community structure of D. latifrons.

\section{ACKNOWLEDGMENTS}

The authors thank the students of the Marine Ecology Academic Unit, UAG, for their help in the field and laboratory. We are also grateful to Guillermo Salgado-Maldonado and David Osorio-Sarabia for their assistance in identifying some of the parasite species. We thank two anonymous reviewers whose extensive and thoughtful comments substantially improved the manuscript. This research was financed by the Sistema de Investigación Benito Juárez (SIBEJ) (19990502017), and the Promep Program.

\section{RESUMEN}

Entre abril del 2000 y junio del 2002 se efectuó un estudio para determinar la composición y la variación temporal en la estructura de la comunidad de parásitos metazoarios del popoyote Dormitator latifrons en la laguna de Tres Palos, Guerrero, México, a partir de muestras temporales. Se recuperaron diez especies de parásitos (55 817 individuos) de 219 hospederos examinados. Estas especies incluyeron ocho helmintos (Ascocotyle (Phagicola) longa, Echinochasmus leopoldinae, Clinostomum complanatum, Pseudoacanthostomum panamense, Saccocoelioides lamothei, Parvitaenia cochlearii, Contracaecum sp. y Neoechinorhynchus golvani) y dos crustáceos (Argulus sp. y Ergasilus sp.). Cinco de las especies de helmintos registraron variación temporal en su dinámica de infección, la cual fue asociada con cambios ambientales durante las estaciones de secas y lluvias. Las variaciones en la dinámica de infección de estas especies generaron cambios en la estructura de la comunidad a lo largo del tiempo.

Palabras clave: México, Dormitator latifrons, comunidades de parásitos. 


\section{REFERENCES}

Aho, J.M., A.O. Bush \& R.W. Wolfe. 1991. Helminth parasites of bowfin (Amia calva) from South California. J. Helminthol. Soc. Wash. 58: 171-175.

Bush, A.O., J. Fernandez, G.W. Esch \& J.R. Seed. 2003 Parasitism: The diversity and ecology of animal parasites. Cambridge University, Cambridge, England.

Bush, A.O., K.D. Lafferty, J.M. Lotz \& A.W. Shostak. 1997. Parasitology meets ecology on its own terms: Margolis et al. revisited. J. Parasitol. 83: 575-583.

Castro-Aguirre, J.L., H.S. Espinosa-Pérez \& J.J. SchmitterSoto. 1999. Ictiofauna estuarino-lagunar y vicaria de México. Limusa, México D.F., México.

Castro-Rivera, R., G. Aguilar-Benitez.\& J. HernándezGirón. 2005. Conversión alimenticia en engordas puras y mixtas de Popoyote (Dormitator latifrons) en estanques de cemento. Aquatic 23: 45-52.

Choudhury, A. \& T.A. Dick. 2000. Richness and diversity of helminth communities in tropical freshwater fishes: empirical evidence. J. Biogeogr. 27: 935-956.

Esch, G.W., C.R. Kennedy, A.O. Bush \& J.M. Aho. 1988. Patterns in helminth communities in freshwater fish in Great Britain: alternative strategies for colonization. Parasitol. 96: 519-532.

Fellis, K.J. \& G.W. Esch. 2004. Community structure and seasonal dynamics of helminth parasites in Lepomis cyanellus and L. macrochirus from Charlie's pond, north Carolina: host size and species as determinants of community structure. J. Parasitol. 90: 41-49.

Fiorillo, R.A. \& W.F. Font. 1999. Seasonal dynamics and community structure of helminths of spotted sunfish, Lepomis miniatus (Osteichthyes: Centrarchidae) from an oligohaline estuary in Southeastern Louisiana, U.S.A. J. Helminthol. Soc. Wash. 66: 101-110.

Garrido-Olvera, L., L. García-Prieto \& B. MendozaGarfias. 2004. Helminth parasites of the fat sleeper, Dormitator latifrons (Richardson, 1844) from Tres Palos Lagoon, Guerrero, Mexico. Am. Midl. Nat. 151: 163-169.

Holmes. J.C. 1990. Helminth communities of marine fishes. In G.W. Esch, A.O. Bush \& J.M. Aho (eds.). Parasite communities: Patterns and Process. Chapman, London, England.

Holmes, J.C. \& P.W. Price. 1986. Communities of parasites in chapter 9. In J. Kikkawa \& D.J. Anderson (eds.). Community ecology: Patters and process. Chapman, London, England.
Jiménez, M.I. 2003. Estructura temporal de las comunidades de parásitos metazoarios en poblaciones de cíclidos silvestres (Cichlasoma urophthalmus) e introducidos en Mitza, Yucatán: un enfoque experimental. Tesis Doctoral, Cinvestav IPN, Mérida, México.

Kennedy, C.R., A.O. Bush \& J.M. Aho. 1986. Patterns in helminth communities: Why are bird and fishes different?. Parasitol. 93: 205-215.

Kennedy, C.R. 1990. Helminth communities in freshwater fish: structured communities or stochastic assemblages? In G.W. Esch, A.O. Bush \& J.M. Aho (eds.). Parasite Communities: Patterns and Processes. Chapman, London, England.

Klimpel, S., A. Seehagen \& H.W. Palm. 2003. Metazoan parasites and feeding behaviour of four small-sized fish species from the central North Sea. Parasitol. Res. 91: 290-297.

Krebs, C.J. 1999. Ecological methodology. Harper Collins, New York, USA.

Lamothe-Argumedo, R. 1997. Manual de técnicas para preparar y estudiar los parásitos de animales silvestres. AGT, México D.F., México.

Marcogliese, D.J. 2001. Pursuing parasites up the food chain: Implications of food web structure and function on parasite communities in aquatic systems. Acta Parasitol. 46: 82-93.

Pérez-Ponce de León, G., L. García-Prieto, B. MendozaGarfias, V. Léon-Règagnon, G. Pulido-Flores, C. Aranda-Cruz \& F. García-Vargas. 1999. IX. Biodiversidad de helmintos parásitos de peces marinos y estuarinos de la Bahía de Chamela, Jalisco. List faun Méx. UNAM, México D.F., México.

Pilo-Guzmán, T. 2003. Evaluación de los parásitos metazoarios que atacan a Mugil curema, Dormitator latifrons, Ariopsis guatemalensis, Eleotris pictus, Cichlasoma trimaculatum, Gobiomorus maculatus, Centropomus robalito y Centropomus nigrescens, especies de mayor consumo local, que se capturan en la laguna de Tres Palos Gro., México. Tesis Maestría, Univ. Autón. Gro., México.

Pineda-Lopez, R. 1994. Ecology of the helminth communities of cichlid fish in the flood plains of Southeastern México. Ph D Thesis, University of Exeter, Exeter, England.

Poulin, R. 2000. Variation in the intraspecific relationship between fish length and intensity of parasitic infection: biological and statistical causes. J. Fish. Biol. 56: $123-137$. 
Rohde, K. 2005. Ecology of marine parasites. CSIRO, Wallingford, Oxon, UK.

Salgado-Maldonado, G. 1993. Ecología de helmintos parásitos de Cichlasoma urophthalmus (Günter) (Pisces: Cichlidae) en la Península de Yucatán, México. Tesis Doctoral, Cinvestav-IPN Unidad Mérida, Mérida, México.

Salgado-Maldonado, G., R. Pineda-López, L. GarcíaMagaña, S. López-Jiménez, V.M. Vidal-Martínez \& M.L. Aguirre-Macedo. 2005. Helmintos parásitos de peces dulceacuícolas. In J. Bueno, F. Álvarez \& S. Santiago (eds.). Biodiversidad del estado de Tabasco., Instituto de Biología, UNAM-CONABIO, México D.F., México.

Stuardo, J. \& M. Villarroel. 1974. Aspectos ecológicos y distribución de los moluscos en las lagunas costeras de Guerrero, México. An. Inst. Cienc. Mar y Limnol. UNAM, México D.F., México.

Vidal-Martínez, V.M., L. Aguirre-Macedo, T. Scholz, D. González-Solís \& E.F. Mendoza-Franco. 2001. Atlas of helminth parasites of Cichlid fish of Mexico. Academy of Sciences of the Czech Republic, Prague.
Violante-Gonzalez, J., Aguirre-Macedo, M.L. \& VidalMartínez, V.M. 2008. Temporal variation in the helminth parasite communities of pacific fat sleeper Dormitator latifrons, from Tres Palos lagoon, Guerrero, Mexico.

Yañez-Arancibia, A. \& G. Díaz-González. 1977. Ecología trofodinámica de Dormitator latifrons (Richardson) en nueve lagunas costeras del Pacífico de México (Pisces: Eleotridae). An. Inst. Cienc. Mar y Limnol. UNAM 4: 125-140.

Zander, C.D., L.W. Reimer \& K. Barz. 1999. Parasite communities of the Salzhaff (Northwest Mecklenburg, Baltic Sea). I. Structure and dynamics of communities of littoral fish, especially small-sized fish. Parasitol. Res. 85: 356-372.

Zander, C.D. 2004. Four-year monitoring of parasite communities in gobiid fishes of the south-western Baltic. II. Infracommunity. Parasitol. Res. 93: 17-29.

Zander, C.D. 2005. Four-year monitoring of parasite communities in gobiid fishes of the southwest Baltic. III. Parasite species diversity and applicability of monitoring. Parasitol. Res. 95: 136-144. 
